\title{
Kisan Credit Card and its Impact on Financial Inclusion in India
}

\author{
Jyoti Mishra $^{1}$ \& Dr. Amar Kumar Chaudhary ${ }^{2}$ \\ ${ }^{1}$ Research Scholar Ranchi University \\ ${ }^{2}$ Associate professor University Dept. of Commerce Ranchi University, India \\ DOI - http://doi.org/10.37502/IJSMR.2022.5206
}

\begin{abstract}
The Kisan Credit Card (KCC) scheme is an innovative step to help Indian farmers for fulfilment of country's agricultural production needs by accessing the short term credit from the nationalized financial institutions. The KCC enables the farmers to purchase various agriculture products like seeds, pesticides, fertilizers and also facilitates for cash withdrawal to enhance the access to finance for the farmers and Financial Inclusion (FI) in India. As India's general economic development has accelerated in recent years. Although KCC credit growth varies by district and slow considerably in certain regions. These trends are expected to persist in Indian agriculture unless sufficient funds or technical solutions are made to boost agricultural output. The purpose of this article is to conduct a systematic assessment for the Kisan (Farmer) Credit Card Scheme (KCCS), which was introduced by the Indian government in 1998-1999 to ease agricultural credit to farmers. Additionally, contribute to financial inclusion via KCC loans. Local governments and financial institutions should provide an encouraging environment that enables farmers and geographical regions to increase their credit process ability, while simultaneously accelerating credit flow and debt recovery.
\end{abstract}

Keyword: Agricultural productivity, Kisan credit card, Kishan credit card scheme, financial inclusion.

\section{Introduction}

Agriculture is the backbone of the Indian economy, with about $70 \%$ of the people relying on it directly or indirectly for their livelihood. One of the most significant problems facing Indian banks has been the creation of a comprehensive system for timely and adequate agricultural and rural loan distribution. Agriculturalists depend heavily on non-institutional or disorganised sources of finance due to frequent credit needs, inadequate institutional credit availability, unreasonable delays, inconvenient processes, red-tapism, and unsuitable lending agency practises. Recognizing agriculture's predominance, rural credit provisions, and the need to reduce farmers' reliance on unorganised sources of credit, the Government of India launched the KCC scheme in 1998 in discussions with the NABARD and RBI to deliver term loans for agricultural needs, which was a ground-breaking credit distribution. All Indian banks, RRBs, and cooperative banks are participating entities. Farmers may apply for collateral-free loans up to Rs. 1 lakh under this KCC programme. The first-year loan amount is determined by the cost of cultivation, post-harvest expenditures, and farm upkeep. The loan will be sanctioned 
depending on the growth in the size of financing over the next five years. The premium is split 2:1 between the bank and the borrower under this arrangement. Interest is charged on loans under the KCC programme at a rate of about 7\% simple interest per year. In the event of nonpayment by the due date, interest is calculated at the card rate, and interest is compounded halfyearly [2]. Additionally, with KCC, farmers may reduce their reliance on high-interest loans provided by banks and non-institutional or unstructured sources of credit, since the interest rate on KCC is very low. Farmers may repay their loans under this programme based on the harvesting time of the crop for which the loan was given. The KCC scheme has evolved over time to include a variety of new features in addition to crop production financing, including consumption expenditure, farm asset maintenance, term loans for agriculture and allied sectors, the facilities of debit cards, a one-time paperwork facility, built-in budget overruns, and unlimited withdrawals [3]. As of February 2019, different banks have given KCCs to about 6.95 farmers. The greatest proportion $(62 \%)$ is held by cooperative banks, followed by commercial banks (30\%) and RRBs (8 percent). The KCC programme has performed well in "Andhra Pradesh, Gujarat, Haryana, Karnataka, Maharashtra, Punjab, Rajasthan, Tamil Nadu, Uttar Pradesh, and Uttaranchal"[4]. Similarly, as of February 2020, according to information provided by Public Sector Banks and NABARD, 187.03 lakh KCC with a credit limit of Rs 1.76 lakh crore have been sanctioned to farmers across the country under this initiative, which will run until 29th January 2021 [5]. The scheme has gained popularity among farmers and bankers alike.

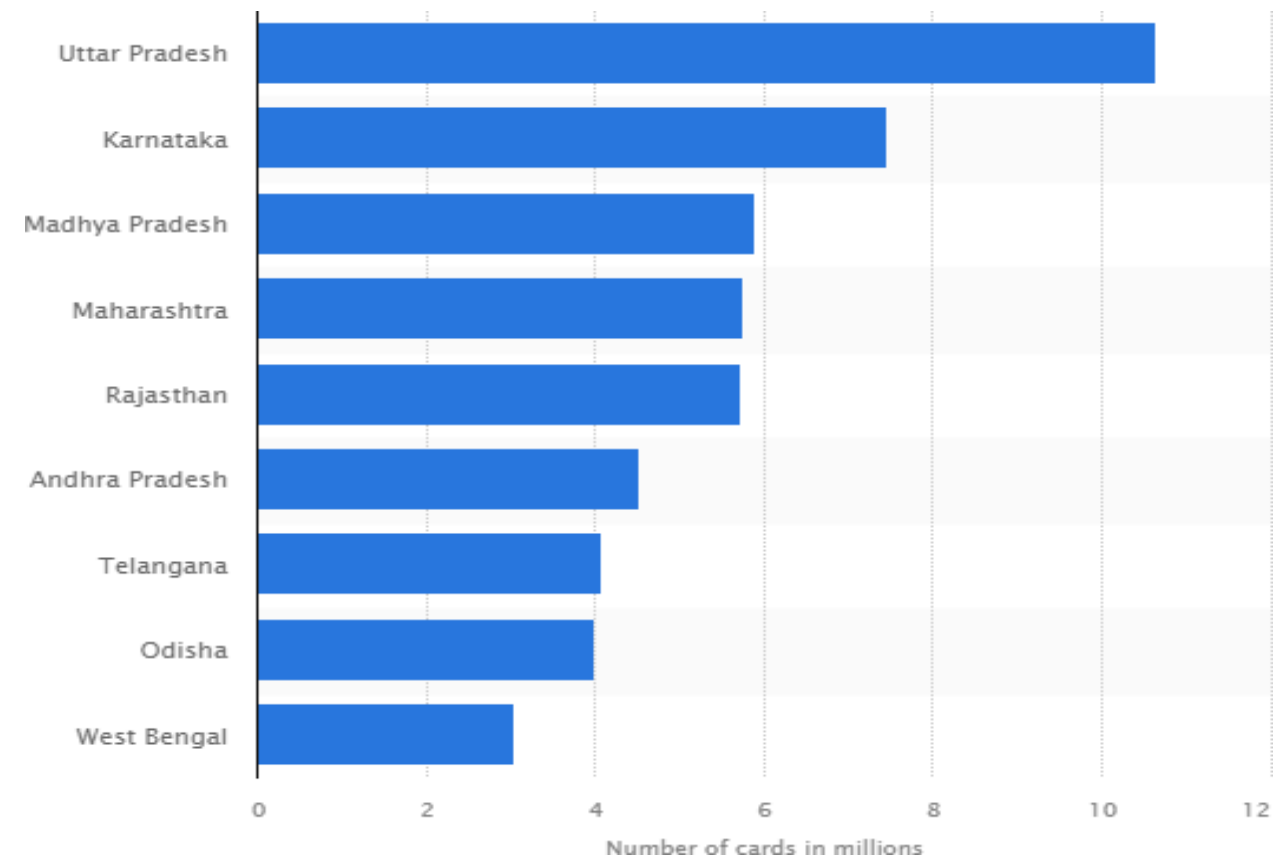

Fig 1: Number of KCC in India FY 2020 [6]

In the fiscal year 2020, the Indian state of Uttar Pradesh issued over 10 million credit cards under the KCCS. Karnataka and Madhya Pradesh came in second and third place with 7.5 million and almost 6 million cards, respectively. There were 65 million active cards in total that year, a small drop from the previous year. The outstanding value of agricultural loans in India was 6.97 trillion rupees [6].Today, $\mathrm{KCC}$ is considered to be one of the best banking products for farmers. The implementation of the $\mathrm{KCC}$ scheme has benefited farmers to a greater 
extent, and farmers can generate more profit, in spite of varying degrees. A special drive to cover farmers under the $\mathrm{KCC}$ has been conducted on a large scale under the initiative of Government of India to boost the Financial Inclusions within the country under the KCC scheme.

\section{Literature review}

Mehta et al. [7] examined the role of rural India's KCCS. The study's main objective was to assess the function of the KCCS and to provide recommendations. It was found that the KCC was a highly effective rural credit instrument for farmers to fund their needs prudently. Banks, it was recommended, should simplify the procedure so that farmers in low-performing zones may also profit from the programme.

R.D Patil et al. [8] in India, the KCCS was evaluated for its impact in promoting FI by looking at how many cards were issued and how much credit was given to cardholders by different bank groups. It was discovered that all of the major bank groups made substantial contributions to the KCCS, which provided financial assistance to low-income farmers. Commercial banks, on the other hand, played a larger role than the other two categories. It was noted that cooperative banks were experiencing difficulties as a result of political meddling and poor management. It was proposed that cooperative banks be protected by minimising political intervention in order to encourage the cooperative sector.

P. Sarkar et al. [9] evaluated the development and performance of Assam's KCCS. One of the main goals of the research was to find out why the KCC plan was moving so slowly throughout the states. A pre-structured survey questionnaire was used to collect data from 80 study participants. As a result, the state's sluggish development was blamed on a variety of factors including natural catastrophes, tiny land holdings, complex paperwork, a paucity of education, payment defaults, inadequate loan amounts, and the uncooperative behavior of bank employees. It was recommended that farmers be educated about the KCCS and that banks streamline the paperwork process.

S. Gandhimathi et al. [10] assessed the role of the KCCS in India's agricultural loan distribution. Among the chosen factors, it was discovered that rural branches of commercial banks, aggregate deposits, agricultural output, commercial bank borrowing from the RBI, and the implementation of the KCCS all had a major role in determining FI. Additionally, regression and logit analyses demonstrated that KCC increased FI in the agricultural sector.

J. Nerella [11] conducted an examination of the KCC scheme's function in agriculture. The KCCS was deemed an innovative and generally appreciated product that benefited farmers. The research demonstrated good improvement, with KCC recipients achieving a better gross return per hectare on all crops examined. $\mathrm{KCC}$ has been shown to have no connection with crop loan, despite the fact that $72 \%$ of agricultural loans were provided in the form of KCC. Additionally, it was recommended that the process for establishing a bank account be simplified, and that village-level campaigns be conducted to recruit more farmers.

\section{Significance of the KCC scheme [12-13]}


$>$ Farmers must have access to sufficient and timely financing.

$>$ Borrower's credit need for a whole year.

Minimum paper burden and simplicity of paperwork required for bank withdrawals.

Flexibility to withdraw cash at any time and purchase inputs as required by the farmer, as well as the ability to return as and when excess funds become available.

$>$ Guaranteed loan availability at all times, resulting in a lower interest burden for the farmer.

The facility will be sanctioned for a period of three years, subject to yearly review, acceptable operation, and provision for expansion.

- Flexibility in withdrawing funds from a financial institutions branch different than that of the bank.

> Personal Accident Insurance Scheme covers KCC holders against accidental death or permanent disability up to a limit of Rs. 50000/- and Rs. 25000/-, respectively. The card issuing institutions and the borrower will split the premium cost in a 2:1 ratio. Bankers encouraged tenant farmers/sharecroppers/oral lessees/joint liability groups to issue KCC.

\section{Importance of KCC in India's Financial Inclusion}

Financial inclusion is a critical facilitator of poverty reduction and wealth growth. Promoting financial inclusion enables whole communities to thrive cooperatively and achieve overall inclusive economic development. Financial inclusion refers to the availability of usable and cheap financial goods and services, such as savings, insurance, credit, payments and transactions. The primary step toward FI is having a transaction account. Since it enables individual to save, transfer, and receive money [14]. The overarching goal of financial inclusion is to increase access to banking services throughout the nation, for both wealthy and underprivileged individuals, under reasonable terms and conditions. With a similar emphasis, the RBI has been encouraging the banking industry to expand its network via the establishment of new concrete block, the expansion of business correspondents, and the addition of additional ATMs at every tier [15]. Over the last decade, numerous initiatives such as the establishment of a no-frills zero balance have been implemented. The government has already introduced Jan Dhan accounts, DBT programmes, the issue of RuPay cards, the issuance of KCC, Aadhaarenabled programmes, and a single payment interface. Indian men's account ownership rose from over $62 \%$ in 2014 to 83 percent in 2017. Females' participation increased from $43 \%$ in 2014 to nearly $76 \%$ in 2017 [16]. 


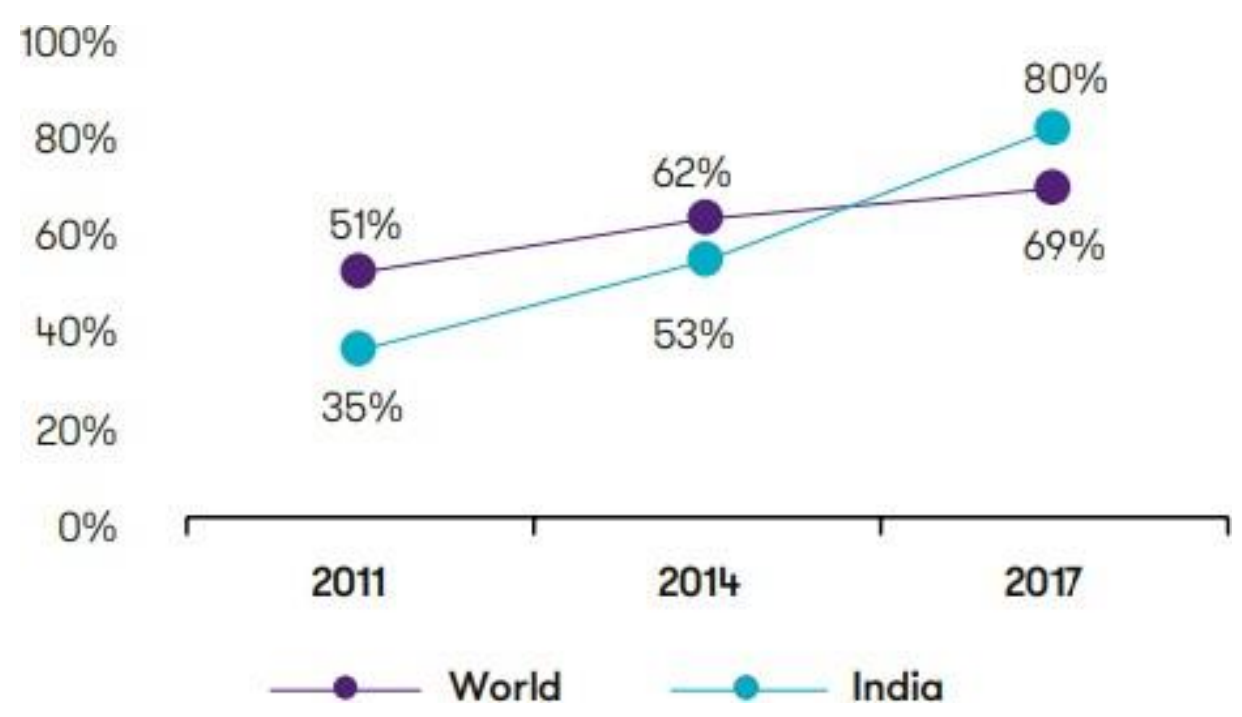

Fig 2: Report on India's financial inclusion [16]

National Strategy for Financial Inclusion (NSFI) for India 2019-24, in which FI has increased significantly and the government of India is aggressively promoting digital financial services [16]. In 2019, the RBI and the Financial Inclusion Advisory Committee (FIAC) developed the NSFI for India 2019-24 with inputs and recommendations from the Indian government and financial industry authorities such as SEBI, IRDA, and others. The government intends to make formal financial services available, accessible, and cheap to all Indian people in a secure and transparent way via this approach. Government delivered a speech as part of its financial inclusion initiative in which he discussed financial literacy, credit counselling, the $\mathrm{BC} / \mathrm{BF}$ model, KYC standards, KCC/GCC, no-frill accounts, branch development, and mobile banking [17]. It is discovered that the KCC has grown at a rapid pace so far, and the fastest increase is anticipated to be recorded by RRBs in terms of the number of KCC issued and the amount sanctioned. Additionally, significant differences in KCC issued were discovered across different states. It is suggested that farmers be educated and encouraged about the programme, and that the scheme be expanded to include all farmers to decrease the cost of loans. [18]. although it's a tough task and need patience to enhance financial inclusion yet several steps have been taken by the Indian government so far. The KCC which has emerged to address the anomalies in distributional aspect of credit. It has been evaluated that in India the scheme of KCC have been expanded at faster pace through cooperative and RRB. It is provided by both the formal and informal sources such as Cooperative Banks, Commercial banks and RRBs. Among Financial Institutions, Co-operative banks are playing vital role in providing credit at affordable rate of interest Kisan Credit Cards have been proved an indispensable tool to speed up the financial reforms by providing support to its Agricultural Credit Market [19-20].

\section{Conclusion}

Agriculture is the foundation of the Indian economy and the most significant industry. Any change in the agricultural sector has a ripple effect across the economy. As a result, agriculture's sustainable development is critical to India's economic growth. Agriculture's growth is affected by a variety of variables, including irrigation, market conditions, infrastructure, and finance. Credit is a critical component in agriculture's sustainable growth. The Indian government has 
made numerous measures in the area of agricultural finance. One of these is the Kisan Credit Card. The KCC programme has made a major contribution to the farm operation and revenue of Indian farmers. To attract more farmers, the procedure of establishing bank accounts should be streamlined. This may be accomplished by conducting local campaigns for the issue of KCCs, raising awareness among the younger population, and providing frequent reminders to farmers about the programme and its advantages from bank personnel. Similarly, widening educational experience and organising training on optimised farming techniques may assist in empowering farmers to adopt the KCC scheme, which will directly benefit the overall economy of the country and the Indian banking industry's capacity to integrating multiple suggestions to achieve financial inclusion.

\section{References}

1) NABARD, "Study on Implementation of Kisan Credit Card Scheme", Department of Economic Analysis and Research, 2016

2) Kumar, V. K. Sonkar, and A. K. S., "Assessing the impact of lending through Kisan Credit Cards in rural India: Evidence from Eastern India," 2021. doi:10.2499/p15738coll2.134240

3) Tanna, "The Role of Data Analytics in Kisan Credit Card for Sustainable Development," International Journal for Research in Applied Science and Engineering Technology, vol. 9, no. VI, pp. 1157-1165, Jun. 2021.

4) K. Patil, "Agriculture development through kisan credit card scheme in western Maharashtra/", International Journal in Management and Social Science, Volume 09 Issue 2, 2021

5) R. Kurup, "Kisan Credit Card System: A Blessing to Small Farmers in India," International Journal for Research in Applied Science and Engineering Technology, vol. 9, no. VI, pp. 5206- 5208, Jun. 2021.

6) Statista Research Department, Number of Kisan Credit Cards in India FY 2020, by state, 2021, https://www.statista.com/statistics/1245872/india-number-of-kisan-creditcards-by-state/

7) Mehta, D., Trivedi, H., Mehta, N.K. (2016). Indian Kisan Credit Card Scheme: An Analytical Study .Brand, Broad research in Accounting, Negotiation and Distribution, 6(1), 23-27.

8) Patil, R. D. (2014), "Role of Commercial Banks in Financial Inclusion through Kisan Credit Card Scheme in India”, International Journal of Multidisciplinary Educational Research, Vol. 3, No. 5 (4), pp. 31-46.Retrieved from www.isrj.org/UploadedData/4332.pdf.

9) Sarkar, P.; Barman, K. K. (2014), "Progress and Performance of Kisan Credit Card Scheme in Assam: A CaseStudy in Kamrup District", The International Journal of Humanities \&Social Studies, Vol. 2, No. (3), pp. 101-105. Retrieved from www.theijhss.com/march 2014/21.HS1403-027.pdf

10) Gandhimathi, S.; Sumaiya, M. (2015), "Role of Kisan Credit Card System in the Distribution of Agricultural Credit in India", International Journal in Management and Social Science, Vol. 3, No. (2), pp. 464-472. Retrieved from www.ijmr.net.in/download.php?filename $=$ jClaFyMT88jcEx9.pdf\&new... 
11) Nerella; J. (2015), "The Role of Kisan Credit Card: Agriculture in India", Global Journal for Research Analysis, Vol.4, No. (5), pp. 167-168. Retrieved from www.worldwidejournals.com/gra/file.php?val= May_2015. 61.pdf

12) Hardarshan Kaur \& Navkiranjit Kaur Dhaliwal, "Progress of Kisan Credit Card Scheme in India”, Amity Journal of Agribusiness,3 (1), pp.26-36,2018

13) Rajamohan, S.; Subha, K. "Kisan Credit card Scheme in India: A Facet of Financial Inclusion”, International Journal of Scientific Research, Vol. 3, No. 10, pp. 234-236, 2014 ,

Retrieved from www.worldwidejournals.com/ijsr/file.php?val=October_2014...70

14) World bank group, "Financial inclusion", https://www.worldbank.org/en/topic/financialinclusion/overview

15) S. R. Samantara, "Financial Inclusion Through Kisan Credit Cards in Arunachal Pradesh - The Truth Behind Aggregating Numbers," Inequality, Poverty and Development in India, pp. 145-158, 2017.

16) Financial inclusion in rural India Banking and ATM sector in India January 2020 , https://www.vakrangee.in/pdf/reports_hub/financial-inclusion-in-rural-india-28jan.pdf

17) M. Sumaiya and S. Gandhimathi, "Impact of Kisan Credit Card Scheme on Financial Inclusion in Agricultural Sector," Asian Journal of Research in Banking and Finance, vol. 5, no. 2, p. 175, 2015.

18) Reetu (2015), "Trends and Progress of Kisan Credit Card Scheme in India", Global Journal for Research Analysis, Vol. 4, No. (9), pp. 329-331. Retrieved from www.worldwidejournals.com/gra/file.php?val=September_2015.

19) Financial inclusion, Europe and Central Asia Economic Update Office of the Chief Economistb Spring 2019, world bank group https://documents1.worldbank.org/curated/en/377571554411400279/pdf/FinancialInclusion.pdf

20) Raheem, "Factors Determining Kisan Credit Card Beneficiary and Non-Beneficiary Farmers in the Farm Economy of Tamil Nadu: An Application of Cobb-Doulas Model," Journal of Economic Studies and Financial Research, vol. 1, no. 1, pp. 9-15, Nov. 2020. 